Annals of Plant Sciences

\title{
Isolation and identification of chemical compounds from stem and roots of Sesbania sesban
}

Baljinder Singh ${ }^{1,2 *}$, Rajiv Sharma ${ }^{3}$, A.N. Kalia ${ }^{4}$, Vijender Kumar ${ }^{5}$

${ }^{1}$ Lala Lajpat Rai College of Pharmacy, Moga - 142001, Punjab, India.

2I. K. G. Punjab Technical University, Kapurthala - 144603, Punjab, India.

${ }^{3}$ Sri Sai College of Pharmacy, Manawala, Amritsar - 143115, Punjab, India.

${ }^{4}$ Sri Sai College of Pharmacy, Badhani, Pathankot - 145001, Punjab, India.

${ }^{5}$ University Institute of Pharmaceutical Sciences \& Research, BFUHS, Faridkot-151203, Punjab, India.

Received: 9/5/2017; Accepted: 9/17/2017

\begin{abstract}
Sesbania sesban is a small perennial tree with woody stems, yellow flowers which is commonly known as Rawasan, family Leguminosae, is one of the restorative plant for inflammatory rheumatic conditions. This study on identification and characterization of isolated chemical compounds from $n$-butanol extract of root and stems of the plant S. sesban. This research is continued from previous research which is done by preliminary phytochemical screening and biological evaluations of extracts. The $n$-butanol extract was selected for compound isolation with column chromatography and identified by UV-VIS Spectrophotometer, FTIR, Mass and NMR Spectroscopic analysis. The results showed the isolated compounds identified as $\beta$-Sitosterol and Kaempferol.
\end{abstract}

Keywords: Sesbania sesban, n-butanol extract, $\beta$-Sitosterol, Kaempferol.

\section{Introduction}

The World Health Organization (WHO) estimates that about $80 \%$ of people living in developing countries rely almost exclusively on traditional medicines for their primary health care needs (Ahmad et al., 2013). Herbals which form a part of our nutrition and provide us an additional therapeutic effect are in demand and Sesbania sesban Linn. is one of such plant (Rafiqkhan and Saranya, 2013). Sesbania sesban (Family- Leguminosae) is a small perennial tree with woody stems, yellow flowers which is commonly known as Jayant (Bengali), Sesbania (English), Rawasan (Hindi) and Karunchembai in Tamil (Pathak and Das, 2013). The flowers of Sesbania sesban have been reported to have Cyanidin and delphinidin glycosides, flavonols. The seeds of $S$. sesban have been reported to have saponins, palmitic acid, stearic acid, lignoceric acid, oleic acid and linolenic acid. The leaves of S. sesban have been reported to have kaempferol (Kinghorn, 2001). Traditionally the plant is used in the treatment of inflammatory rheumatic conditions, diarrhea, in excessive menstrual flow, to reduce enlargement of spleen and in skin diseases (Kumar et al., 2014). The aim of this study is isolation and identification of $n$-butanol extract from root and stems of $S$. sesban. It also includes of screening phytochemicals, fractionation, isolation by TLC, Column Chromatography and the identification using spectroscopy methods.

${ }^{*}$ Corresponding Author:

Mr. Baljinder singh

Lala Lajpat Rai College of Pharmacy,

Moga-142001, Punjab, India.

E-mail: bajwabalijinder1@gmail.com

\section{Materials and Methods}

Collection and authentication of the plant

The dried plant materials root and stem of Sesbania sesban were collected from S V University, Tirupati, Andhra Pradesh and botanical authentication has been obtained from Dr. K. Madhava Chetty, S V University, Tirupati, Andhra Pradesh.

\section{Preparation of Extract}

The air dried powdered plant material stems and roots of Sesbania sesban were extracted with methanol in a Soxhlet extraction apparatus. The solvent was removed under reduced pressure and semi solid mass was obtained (yield 7.75\%). The total methanolic extract was concentrated to dryness in vaccuo at $35^{\circ} \mathrm{C}$. Active constituents from the dried extracts were separated by column chromatography with different solvent ratio and evaluated for phytochemical screenings and anti-inflammatory activity. The most bioactive n-butanol fraction was selected for isolation of phyto constituents.

\section{Isolation and characterization of} phytoconstituents

$2 \mathrm{~kg}$ air dried and coarsely powdered stems and roots of $S$. sesban were defatted with petroleum ether (40 $60^{\circ} \mathrm{C}$ ) extracted in soxhlet extractor for $72 \mathrm{~h}$. Then, the solvent free marc was again successively extracted with chloroform, ethyl acetate, n-butanol, methanol and finally decocted with distilled water. All the extracts was concentrated with rotaevaporator and transferred to a tarred china dish and kept in vacuum dessicator. The most bioactive n-butanol extract was further used for isolation of 
compounds. The yields of successive extracts were obtained as petroleum ether $40-60^{\circ} \mathrm{c}$ (320g), chloroform (187.3g), ethyl acetate (165.32g), methanol (312.11g) and aqueous (387.52g). Successive extracts were used for phytochemical screenings. Target based compounds were isolated from most active extracts.

\section{Fractionations and isolation of compounds} from stem extract

Successive petroleum ether extract (320g) was dissolved in chloroform and mixed with silica gel and air dried this mixture. It was packed in column and again first eluted with petroleum ether $\left(40-60^{\circ} \mathrm{C}\right)$ alone, followed by pet. ether: chloroform (95:5 to 90: 10) and chloroform: n-butanol (100:0, 95:5 to 90: 10 to $80: 20.100 \mathrm{ml}$ fractions were collected and combined based on similar profile on TLC and dried over rotary evaporator.

\section{Kaempferol}

Compound was isolated from stem extracts of $S$. sesban. Dark yellow needle/crystalline powder, m.p. was found $276-278^{\circ} \mathrm{C}$. It is Soluble in chloroform and methanol, UV $\lambda_{\max }\left(\mathrm{CH}_{3} \mathrm{OH}\right)=254,266,320$ and $368\left(\mathrm{CH}_{3} \mathrm{OH}+\mathrm{AlCl}_{3}(421,362,344,302,278\right.$ $\mathrm{nm})$. Rf value 0.80 was obtained with solvents system n- Butanol: acetic acid: water (4:1:5) It gave green color with ferric chloride solution and pink color with shinoda test. IR (KBR, $v$ max, $\mathrm{cm}^{-1}$ ): 3429.41 (O-H), 2958.14, 2937.12, 2908.21, 2848.5 (C-H), 1642.60 (C=O), 1379.39 (C-C), 1332.55, $1240.59, \quad 1192.59,1133.57,1106.57,1055.39$, 1023.50, 958.53, 837.60 and Mass spectroscopy quasi-molecular ion peak [M-H] - was found at $\mathrm{m} / \mathrm{z}$ 285 and $[\mathrm{M}+\mathrm{H}]^{+}$at $\mathrm{m} / \mathrm{z}$ 286. The molecular formula $\mathrm{C}_{15} \mathrm{H}_{10} \mathrm{O}_{6}$ was analyzed by mass spectral data. These data were analyzed and compound was identified as Kaempferol.

\section{Fractionations and isolation of compound from root extract}

$\mathrm{n}$-Butanol extract was dissolved in methanol and mixed with silica gel and dried. Dried mixture loaded on top of silica gel (60-120 mesh) column and column was eluted with petroleum ether, chloroform, n-butanol, ethyl acetate and methanol in different ratio. $50 \mathrm{ml}$ fraction were collected and pooled together based on similar TLC profile and solvent was evaporated over rotary evaporator. A total of 18 fractions were collected, and 3 of them were collected because of good yield and one of them is identified as $\beta$-sitosterol.

\section{$\beta$-sitosterol}

It was isolated as white crystalline powder, $\mathrm{mp}$ 136$137^{\circ} \mathrm{C}$; Molecular weight: EI-MS for $\mathrm{m} / \mathrm{z}$ : $414\left[\mathrm{M}^{+}\right]$; Molecular formula is $\mathrm{C}_{29} \mathrm{H}_{50} \mathrm{O}$. UV $\chi_{\max }$ was found as 206. Infrared spectral analysis with KBR pellet methods and major peaks were found as 3410 ($\mathrm{OH}), 2958(\mathrm{C}-\mathrm{H}), 2917(\mathrm{C}-\mathrm{H}), 1662(>=\mathrm{CH} 2)$ 1642, $1440\left(=\mathrm{CH}_{2}\right), 1382(-\mathrm{C}-(\mathrm{Me})$ 2), 1336, 1303 NMR spectral analysis were found as $(100 \mathrm{MHz}$, $\left.\mathrm{CDCl}_{3}\right)$ 8: $36.87(\mathrm{CH} 2, \mathrm{C} 1), 31.52(\mathrm{CH} 2, \mathrm{C} 2), 69.97$ (CH, C3), 41.03 (CH2, C4), 141.10 (Cq, C5), 120.11 (CH, C6), 30.90 (CH2,C7), 30.99 CH,C8), 49.54 (CH,C9), 36.18 (Cq,C10), 20.42 (CH2, C11), 39.56 $(\mathrm{CH} 2, \mathrm{C} 12), 42.14$ (Cq,C13). On the basis of the above studies include HPTLC, UV, IR, MASS and NMR studies the compound has been identified as $\beta$-sitosterol.

\section{Conclusion}

Stems and roots of Sesbania sesban were successively extracted with different organic solvents and most bioactive extract $n$-butanol indicate the presence of flavonoids, tannins and coumarins compounds. Based on the data obtained from chromatographic, UV, IR, NMR and Mass spectrophotometer studies, the isolated compound were identified as Kaempferol and $\beta$-sitosterol

\section{Acknowledgements}

We would like to thanks to management and staff of Lala Lajpat Rai College of Pharmacy, Moga, Punjab (India) by constant support and providing the lab facilities. We also thanks to IKG Punjab Technical University, Kapurthala for constant support for this study.

\section{References}

Ahmad T, Singh SB, Pandey S. Phytochemical screening and Physicochemical parameters of crude drugs: A Brief Review. International Journal of Pharma Research \& Review, 2013, 2 (12), 53-60.

Rafiqkhan M, Saranya. Pharmacognostic profile and Phytochemical investigation on the leaves of Achyranthes aspera. International Journal of Pharmacy and Pharmaceutical Sciences, 2013, 5(3), 368-370.

Pathak K, Das RJ. Herbal Medicine- A Rational Approach in Health Care System. International Journal of Herbal Medicine, 2013, 1 (3), 86-89.

Kinghorn AD. Pharmacognosy in the $21^{\text {st }}$ century. Journal of Pharmacy and Pharmacology, 2001, 53, 135-148.

Kumar S, Bajwa BS, Kumar N. Evaluation of anti-bacterial activity of plant Sesbania sesban. International Journal of Pharmacy, 2014, 4(1), 385-396.

\section{Cite this article as:}

Baljinder Singh, Rajiv Sharma, A.N. Kalia, Vijender Kumar. Isolation and identification of chemical compounds from stem and roots of Sesbania sesban. Annals of Plant Sciences 6.10 (2017) pp. 1718-1719.

doi: http://dx.doi.org/10.21746/aps.2017.10.7 